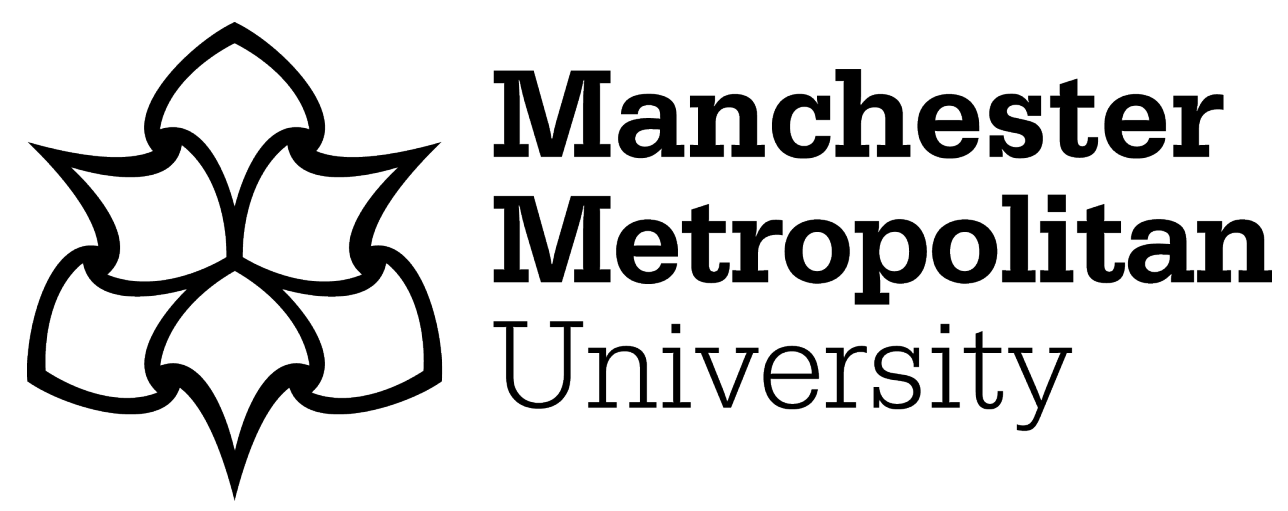

Chapman, Melanie, Lacey, Huma and Jervis, Nicola (2018) Improving services for people with learning disabilities and dementia: Findings from a service evaluation exploring the perspectives of health and social care professionals. British Journal of Learning Disabilities, 46 (1). pp. 33-44. ISSN 1354-4187

Downloaded from: https://e-space.mmu.ac.uk/621966/

Version: Accepted Version

Publisher: Wiley

DOI: https://doi.org/10.1111/bld.12210

Please cite the published version 


\title{
Improving services for people with learning disabilities and dementia: Findings from a service evaluation exploring the perspectives of health and social care professionals
}

\author{
Melanie Chapman $^{1,2}$ (D) | Huma Lacey ${ }^{1}$ | Nicola Jervis ${ }^{1}$ (D)
}

${ }^{1}$ Community Adult Learning Disability Services, Manchester University NHS Foundation Trust, Manchester, UK

${ }^{2}$ Faculty of Health, Psychology and Social Care, Manchester Metropolitan University, Manchester, UK

Correspondence

Nicola Jervis, North Community Learning Disability Team, Crescent Bank, Humphrey Street, Manchester M8 9JS, UK.

Email: nicola.jervis@mft.nhs.uk

\section{Accessible summary}

- Dementia is an illness caused by damage to a person's brain.

- People with learning disabilities, especially people with Down's Syndrome, are more likely to get dementia, and when they are younger.

- We talked to people working in community learning disability teams to find out what they thought about services and support for people with learning disabilities and dementia and carers.

- Screening and assessments mean that people get diagnosis and support more quickly and other problems are picked up.

- More appropriate housing and support is needed so people can stay at home for longer.

- Research needs to look at the best ways to support people with learning disabilities and dementia.

- It is important to find ways to involve people with learning disabilities and dementia and carers in meetings about their support and future research.

\section{Abstract}

Background: Dementia prevalence rates are higher amongst people with learning disabilities than the general population. People with Down's syndrome are at even greater risk of developing dementia and of developing dementia at an earlier age. This study, conducted as part of a wider service evaluation, explored community learning disability team perspectives on screening, pathways, training, information and supports developed to improve services for people with learning disabilities and dementia.

Methods: A focus group was held with health and social care professionals working in community learning disability services. Thematic analysis was used to analyse the data. Results: The dementia screening, pathways and processes had become embedded in practice, leading to a common framework, an efficient, multidisciplinary, proactive approach, earlier detection and diagnosis of dementia and identification of other health needs and issues. This avoided crisis situations supporting people to remain at home longer. Training and information were felt to improve care quality and reduce caregiver anxiety. People with learning disabilities and caregivers were involved to varying extents. External influences impacting on support included the availability, appropriateness, cost and effectiveness of different models of service provision. 
Conclusions: Service developments have been made as a result of the findings which suggest that dementia pathways and supports improve service provision and outcomes for people with learning disabilities. It is important to develop the evidence base on the effectiveness of different service models for people with learning disabilities and dementia. Future studies need to gather views of people with learning disabilities and carers.

\section{KEYWORDS}

dementia, down syndrome, health and social care policy and practice, intellectual disability, learning (intellectual) disabilities, palliative and terminal care, staff training

\section{1 | INTRODUCTION}

The number of people with dementia is increasing as people live longer. Within the general population, $7.1 \%$ of people aged over 65 years will develop dementia and this figure increases the older people get. Prevalence rates are higher amongst people with learning disabilities; prevalence rates in people with learning disabilities without Down's syndrome increase from $10 \%$ of $50-65$ year olds to $14 \%$ of $65-75$ year olds and $25 \%$ of $75-85$ year olds. People with Down's syndrome are at even greater risk of developing dementia and of developing dementia at an earlier age, with prevalence rates rising from $10 \%$ of $40-49$ year olds to $33 \%$ of $50-59$ year olds to over $50 \%$ of people aged 60 years and over (Alzheimer's Society, 2014).

Supporting people with dementia is a national priority. The National Dementia Strategy for improving dementia services in England and consequent Prime Minister's Dementia Challenge and update recognised the increased risk of dementia amongst people with learning disabilities, difficulties receiving a diagnosis and appropriate support, and the importance of health and social care professionals collaborating (Department of Health, 2009, 2012, 2015). Similar strategies have been published in Scotland (Scottish Government, 2013), Wales (Welsh Assembly Government, 2011) and Northern Ireland (Department of Health, Social Services and Public Safety, Northern Ireland, 2011). Services need to work together to provide appropriate support for people with learning disabilities and dementia (Department of Health, 2001) and people with learning disabilities and carers should have access to specialist advice and support (NICE, 2006).

Good practice guidelines emphasise the need for early screening and detection and recommend that all services for people with Down's syndrome have robust baseline assessments of individuals' cognitive, adaptive and social functioning before 30 years of age (British Psychological Society, 2015; Turk, Dodd, \& Christmas, 2001). Proactive screening strategies incorporating assessments of physical, medical, psychological, cognitive and behavioural function are needed to discount conditions other than dementia, for early identification of need and appropriate intervention (Kalsy et al., 2005). The British Psychological Society (2015) recommends that diagnosis involves a multidisciplinary process and every learning disability service have a register of all adults with Down's syndrome. Services should also develop specialist skills, offer training to professionals and carers and build effective interagency co-ordination (Turk et al., 2001).

There is little research evidence to inform interventions for people with learning disabilities and dementia. NICE guidelines recommend a range of pharmacological and nonpharmacological interventions (structured group cognitive stimulation programs, cognitive behaviour therapy, reminiscence therapy, aromatherapy, multisensory stimulation, music therapy, dancing therapy and animal-assisted therapy, massage and exercise) for dementia (NICE 2006, updated 2017). However, there are difficulties drawing conclusions about the effectiveness of different approaches and interventions for people with learning disabilities and dementia from the existing evidence base. The evidence base on managing dementia amongst the general population is limited, with more research needed on differential responses to specific treatments and the long-term benefits of interventions, including impact on quality of life and social functioning (NICE, 2006, updated 2017). People with learning disabilities are often excluded from dementia research (for example, Spector et al., 2003) and have pre-existing cognitive impairments so findings may not be generalisable to them. People with learning disabilities generally develop dementia at a younger age; therefore, interventions and services developed for, and evaluated with, older people who have dementia but do not have learning disabilities may not be appropriate (Department of Health, 2009, 2012, 2015) and will need to be adapted to make them age appropriate and accessible which may impact on their effectiveness.

Sheehan, Afia, and Hassiotis (2014) highlight that there are few clinical trials assessing the potential benefits of pharmacological treatment approved for use in dementia in the United Kingdom in people with learning disabilities and dementia, and that most trials have focused on dementia in Down's syndrome only (i.e., Hanney et al., 2012; Mohan, Bennett, \& Carpenter, 2009a,b; Mohan, Carpenter, \& Bennett, 2009). Similarly, there is little research exploring the applicability of nonpharmacological interventions recommended by NICE and the BPS for people with learning disabilities and dementia. In 2010, a review found a lack of research focusing on dementia care for people with learning disabilities (Courtenay, Jokinen, \& Strydom, 2010). Since then, there has been some research into components of care, staff knowledge and management strategies and environmental factors for people with learning disabilities and dementia living in group 
homes and special care units (De Vreese et al., 2012; Janicki, Zendell, \& DeHaven, 2010; lacono, Bigby, Carling-Jenkins, \& Torr, 2014). Initial small-scale studies of the use of reminiscence therapy, Singing for the Brain sessions and personalised life story books and rummage boxes suggest that these interventions are acceptable to people with learning disabilities and staff and have the potential to lead to positive outcomes such as supporting communication, memory, social engagement, choice, mood and well-being (Crook, Adams, Shorten, \& Langdon, 2016; Stueber \& Hassiotis, 2012; Ward \& Parkes, 2015).

Other papers describe the development of specialist services, screening and support for people with learning disabilities and dementia in England. These tend to focus on the practicalities of establishing services and screening strategies (e.g., screening frequency, whether assessments are completed directly with people with learning disabilities or informants). They also discuss issues arising as screening and support are introduced; for example, the importance of a multidisciplinary approach, services working together, caregiver training and awareness-raising and personcentred, flexible assessments, the role of screening in identifying additional health and social care needs and increasing screening uptake (Cairns, Lamb, \& Smith, 2010; Hobson et al., 2012; Jervis \& Prinsloo, 2008; Kalsy et al., 2005; Starkey, Bevins, \& Bonell, 2014).

This paper adds to the limited evidence on specialist dementia services for people with learning disabilities by exploring their impact several years post-introduction from the perspectives of health and social care professionals based within community learning disability teams. Locally, these teams consist of community learning disability nurses, psychologists, speech and language therapists, occupational therapists and physiotherapists employed by a local NHS organisation providing hospital and community services. These health professionals are co-located with care managers and social workers employed by the local authority. Psychiatry provision is commissioned from a NHS mental health service provider. A multidisciplinary dementia working group established in 2002 implemented a number of service developments (Table 1). After these were in place for several years, a service evaluation was conducted which aimed to review the effectiveness of the service developments and to ensure that local services were meeting the needs of people with learning disabilities and dementia. Specific questions relating to this aim were to identify:

1. Whether anything had changed as a result of the service developments (for professionals, people with learning disabilities and carers)

2. Whether there had been any benefits from the service developments

3. Areas for improvement

An important aspect of the service evaluation was to explore health and social care professionals' experiences and perspectives of the service developments. This paper reports the findings from a focus group conducted to gather information to meet these aims and questions.

\section{2 | METHODS}

One focus group was held with health and social care practitioners with direct experience of the dementia processes and supports as part of a service evaluation. Focus groups involve organised discussion with a group of people to gather information about their views and experiences of a topic. The group interaction can produce a range of views, attitudes, beliefs and feelings which may not be obtained using other methods and support information-gathering from more participants
TABLE 1 Dementia processes and supports

\begin{tabular}{|c|c|}
\hline Dementia screening & $\begin{array}{l}\text { Everyone with Down's Syndrome is offered a baseline assessment } \\
\text { between the ages of } 25-30 \text { years, followed by ongoing reassess- } \\
\text { ment (Backer \& Jervis, 2007; Jervis \& Prinsloo, 2008). }\end{array}$ \\
\hline $\begin{array}{l}\text { Assessment and } \\
\text { diagnosis pathway }\end{array}$ & $\begin{array}{l}\text { Involves health checks by the GP, referral to psychology, other } \\
\text { professional groups and memory service. }\end{array}$ \\
\hline $\begin{array}{l}\text { Dementia interventions } \\
\text { pathway }\end{array}$ & $\begin{array}{l}\text { Specifies an initial multidisciplinary dementia review meeting with a } \\
\text { set format, followed by regular reviews (approximately every } \\
6 \text { months depending on client circumstances). }\end{array}$ \\
\hline $\begin{array}{l}\text { Dementia interventions } \\
\text { checklist }\end{array}$ & $\begin{array}{l}\text { Records whether known interventions have been considered (for } \\
\text { example, life story work, behaviour guidelines, environmental } \\
\text { modifications, communication support, dysphagia management, } \\
\text { mealtime plan, medication, reality orientation, reminiscence, } \\
\text { validation). Aims to ensure that every person with dementia known } \\
\text { to the service has equal access to all available interventions rather } \\
\text { than interventions being offered according to an individual } \\
\text { practitioner's knowledge and skills. }\end{array}$ \\
\hline $\begin{array}{l}\text { "Top Tips" information } \\
\text { sheets }\end{array}$ & $\begin{array}{l}\text { Six information sheets to support carers in their caring role; these } \\
\text { discuss nutrition, behaviour that challenges, personal care, } \\
\text { maintaining skills/activity involvement, creating a suitable environ- } \\
\text { ment and communication. }\end{array}$ \\
\hline Training & $\begin{array}{l}\text { Training on dementia awareness and interventions is offered to paid } \\
\text { and family carers through training days and bespoke training. }\end{array}$ \\
\hline
\end{tabular}


in a shorter time period than one-to-one interviews (Kitzinger, 2006; Krueger \& Casey, 2000). A researcher working within the service facilitated the focus group with an assistant psychologist as assistant moderator. A topic guide was used to guide the focus group discussion which was digitally recorded and transcribed per verbatim. The topic guide asked: whether anything had changed as a result of the service developments; what people felt worked well and what could be improved in relation to the service developments; whether people had received feedback from people with dementia and their families, people they live with or support workers about local services for people with learning disabilities and dementia; and gaps in local service provision.

As the focus group was carried out as part of a service evaluation, formal NHS ethical review and research governance approvals were not necessary. However, the service evaluation followed ethical principles. Potential participants were provided with written information sheets and had the opportunity to ask questions to help them to make an informed choice about whether to take part. Participants were assured that their participation was voluntary and signed consent forms to indicate their consent to participate. Participants were informed that information would be anonymised and were asked to treat information shared during the focus group as confidential (unless abuse was reported). Evaluation data (focus group transcripts) were anonymised and stored on secure NHS password servers separate from any personally identifiable information (i.e., consent forms).

\section{1 | Recruitment and participants}

Each professional group within the community learning disability service was invited to nominate one or more people to take part in a focus group. Eight people volunteered to take part and the focus group included representatives from most of the professional groups: social care $(N=1)$, psychology and behavioural support $(N=3)$, occupational therapy $(N=1)$, speech and language therapy $(N=1)$, community learning disability nursing $(N=1)$ and psychiatry $(N=1)$. No one from physiotherapy was available to take part. Participants had worked in the service for 1-34 years.

\section{2 | Analysis}

Thematic analysis, a method for identifying, analysing and reporting patterns (themes) within data, was used to analyse focus group data (Braun \& Clarke, 2006). An inductive, data-driven approach was taken to analysis: themes were identified from data rather than driven by study questions or the evaluation team's theoretical perspectives. Thematic analysis involves six phases: familiarisation with the data, generating initial codes, searching for themes, reviewing themes, defining and naming themes and final analysis and write-up. The analysis was carried out by the three authors: a clinical psychologist, clinical psychology assistant and a researcher based within the community learning disability services. Each author read through transcripts independently to generate initial codes, then met to discuss overlap, agree final codes and identify and name broader themes. Each theme was allocated to two people to code transcripts independently. The authors met again as a group several times to further refine, analyse and write up the themes.

\section{3 | FINDINGS}

This section describes participants' perspectives on the dementia screening, pathways and additional resources, the experiences of people with learning disabilities and carers and the wider context.

\section{1 | Co-ordinated approach}

Participants felt that the dementia screening and pathways had become well-established, embedded practice across the city, providing professionals within the service with a "common framework" and "shared understanding" of processes involved. Having structured processes in place was seen as leading to a more consistent, efficient, co-ordinated, multidisciplinary approach:

Psychologist B: You might have separate conversations otherwise... different clinicians might think of things but we aren't going to think of all the things that the other professions would think of, whereas if you're all in the same room, like if someone mentions eating and drinking then it's obviously great to have a speech and language therapist there to ask the right questions and that seems more efficient.

Screening and the assessment pathway enabled earlier detection of dementia and speeded up the diagnosis process. This meant earlier intervention and detailed information being available about the person to inform the provision of more effective, appropriate support. This contrasted with participants' experiences before the processes were in place, or in other services:

Care Manager: There was much less structure before, you'd be much farther along the process of someone having dementia before you were aware of that. Now obviously as soon as people with Down's syndrome come in to the service they're on the pathway...From my view it's much more structured, it gets people in earlier on, and there's a lot more information about that person and about that condition.

The screening and assessment processes and regular reviews identified health needs and other issues, such as safeguarding concerns, which would have otherwise gone undetected, meaning that people with learning disabilities and caregivers received interventions and support at an early stage:

Psychologist B: ...one of the one main benefits of the dementia processes is that it picks up all the other concerns. So where you might get a couple of people with a diagnosis 
of dementia, but all the other people you've seen, the most people l've worked with, it's actually been something else wrong and that's got treated or they're trying to address the issue. Sometimes there's been safeguarding around poor quality care rather than a health concern actually, stuff like that.

These processes enabled a proactive rather than reactive response, facilitating planning and co-ordination of support to meet changing social and healthcare needs and preventing crisis situations. This resulted in more people staying at home for longer rather than being moved into residential care or a nursing home at a time of crisis.

Participants felt there were advantages of one person completing the majority of screening assessments multiple times. This continuity increased assessments' validity and reliability and helped professionals clarify queries and gain a clearer picture of someone's history:

Psychologist B: having the assistant psychologist....it makes it more consistent in terms of the same person has often assessed the person with learning disability multiple times and seen them at different stages, and I think that increases the validity really and probably the reliability of scoring things in the same way... I've found that helpful when I pick up a case, and having [the assistant psychologist] available to ask questions of about the person and their history.

Everyone diagnosed with dementia is assigned a case co-ordinator, making it easier for caregivers to know who to contact for advice, reassuring carers and increasing their confidence to request support, express concerns and report changes.

\section{2 | Impact of diagnosis}

The implications of receiving a diagnosis of dementia were discussed. A diagnosis could provide a powerful argument for support and resources:

Care Manager: Like me being a care manager, I've got no medical qualifications...if you've got a diagnosis I can quote them back to the report they'll take more notice of me... The diagnosis gives you the clout...It might be a bad analogy but in social care l've got the gun but not the bullets. You guys give me the ammunition. Otherwise I'm shooting blanks.

However, misunderstandings could arise about whether someone had a diagnosis because they were participating in dementia screening:

Occupational Therapist: A social worker had put in the person's reassessment that he had dementia but she'd just seen like one of the reports and then when he went to his new placement they all thought he had dementia because it was in his core assessment.

This could have serious implications for someone's support and distress family members:

Psychologist A: ....the family were really upset because they'd gone to their GP because of concerns and the referral to the GP said that they had dementia so the GP just said out to them you've got dementia haven't you? And they were like, no. And they were like has something changed? What's going on? Nobody told us. They were really panicked, really distressed about it and we had to explain where the mix-up had maybe happened but just to be told very bluntly that your family member's got dementia when they haven't.

\section{3 | Additional resources}

The main methods for increasing carers' knowledge and skills around dementia were training and the "Top Tips" sheets. Participants thought training had improved the quality of care people with learning disabilities and dementia received over the years and increased staff confidence:

Speech and Language Therapist: A few years ago the staff team were really anxious and finding it really difficult to support the lady and constantly on the phone saying 'We're worried about this, we're worried about that'. And now they are just so confident and everything is discussed at the review meetings and training is positive. Bespoke training from different professional groups. They've been really successful.

Although mainly paid staff attended training, family members and adult placement carers also attended and it was felt that their experiences were positive. Challenges surrounded staff finding out about training and being released to attend separate awareness and interventions training days:

Occupational Therapist: The general dementia training, the feedback was very positive...they said can we come and do two days together because they really have to find out from their managers what training's available.

The "Top Tips" sheets were considered to provide helpful information and suggestions to support carers in their caring role:

Nurse: The top tips sheets have been quite a clear structured way of giving people ideas about kind of managing particular challenges. I think the challenging behaviour one got quite good feedback in particular and also the communication one as well. 
Some information sheets may be more helpful than others depending on individual situations, and there might be too much information for some carers; however, it was felt that it is difficult to create a generic resource that meets everyone's needs. Offering information sheets in different languages would also be useful. Other services wanted to use the information sheets, including services for people with dementia without learning disabilities.

Participants discussed the benefits and challenges of integrating the recently introduced Dementia Interventions checklist into practice:

Psychologist B: [The intervention checklist] is useful for make you think about different interventions because if not you have to make yourself a list, so I think it's good we're all using one across the service. And it's quite strict, saying have you thought about it? And if not, why not? And it is quite good to make you think and answer it but it takes time to complete it as well doing it like that.

It was felt that this was better used as a prompt sheet rather than formally filled in during a review meeting.

\subsection{Experiences of people with learning disabilities}

The dementia processes and supports were perceived to help people with learning disabilities maintain independence, retain family links and preserve a sense of personhood. There were examples of people being supported to remain at home rather than being moved to an unfamiliar or inappropriate place (for example, younger people being placed in a ward or nursing home for older people) with potentially negative impacts:

Psychiatrist: I saw a patient recently who was living in supported accommodation with moderate learning disability ....and she developed vascular dementia and she was presenting with loads of risk, risk of fire, self-neglect, dysphagia, and loads and loads of problems...everyone wanted her to be admitted but admitting her on a later life ward, a 30-40 year old lady...ideally she would not benefit from being on an elderly ward where people have cognitive problems but the staff are not trained either and they had their own anxieties... and her behaviour might actually deteriorate, being in hospital, being in an unfamiliar place where she doesn't understand what's happening........They managed to put some more support in place for her .... She got 24-hr support. That is what she needed, she had her own independence as well, and she got the support. That was ideal for her.

People with learning disabilities were involved in the screening, assessment and review processes to varying degrees at different times. This was often on a best interests basis as they might not understand the process and potential impact of assessments. Generally, it was felt that people enjoyed assessments:
Assistant Psychologist: I know that a lot of people who l've done the assessments with they really enjoy them, they enjoy the attention, they enjoy the little activity together.

Although people with learning disabilities did not participate routinely in reviews, there were positive examples of them being involved and contributing:

Care Manager: The customer attended every six monthly review.... How much of it he really understood I couldn't say but he seemed happy enough and he was asked questions about certain things that he was doing and he would answer them appropriately so. But obviously he's not somebody with Down's. He's got vascular dementia and would be in his late 50 s and he's in the first sort of early to middle stage.

Level of involvement was influenced by review location, degree of dementia and learning disability, and whether the review team felt someone could understand and contribute to the review process.

The speed of the progression of dementia meant that people could lose skills, affecting their participation in reviews and discussions. Some conversations could be difficult, for example, about end of life, and sadly, people could die before it was possible to discuss end of life as part of the pathway:

Nurse: People with LD they seem to die so much faster along the process...We probably get a diagnosis and start the process but they die so quickly before we even get round to looking at the [End of Life] booklet.

\subsection{Family experiences}

It was felt that generally family members appreciated the dementia services and supports. There were examples of family members feeling able to make contact due to earlier experiences of the dementia screening process. Family could play a "pivotal," "crucial" role in the diagnosis process, sharing useful information about the person with learning disabilities and their history and helping to ensure that they remain at home as long as possible:

Psychologist C: They were involved in a lot of the sharing knowledge about the person. So where there were questions, discussions being had about the person's care and support and how they maybe might tweak the support and how they might make sense of changes in a person's presentation they were able to offer information about the client, some insight into bits and pieces about their history that just helps to put things into context a little bit. And certainly felt able to say this is what we think should happen. 
However, occasionally family members were seen as acting as gatekeepers, preventing someone with learning disabilities accessing screening, services and support:

Assistant Psychologist: I went back for, well I rang back for a reassessment and the person's sister who looks after him, and she said well he doesn't want to do it ... But it felt more as though it was more to do with his sister than him.

Some family members might find the amount of service input overwhelming, feel they are being monitored or judged or have concerns that their relative might be taken away, particularly if they had not used learning disability services before. As discussed, misunderstandings about diagnoses of dementia could be distressing for family members. It could also be difficult for family to think about end of life issues early on in the dementia review process, and several family members had upsetting experiences when their relative was in hospital (e.g., around the use of Do Not Resuscitate orders). It was important that the level and methods of involvement vary according to family members' preferences and individual situations:

Psychologist B: It depends on the families. We've had some where they really appreciate being involved and then we've had other families where they've wanted the feedback kind of a one to one with me afterwards but have felt that being in the room with everybody, particularly talking about certain areas they just felt too difficult. So they're still engaged with the process, like we did some feedback before so their thoughts could be shared in the meeting and then I fed back afterwards and sent them the minutes. For them personally the bodies in the room I think it was just a bit too much.

\subsection{Experiences of paid carers}

Participants felt paid carers benefitted from a co-ordinated service response and recommendations, which alongside training and a quick response in times of crisis, helped them feel supported, less anxious and better able to cope, improving the support people with learning disabilities and dementia receive. Contact with a range of professionals increased knowledge of the range of available support. Review meetings provided a way for paid carers to be actively involved:

Care Manager: Some of the better [providers] where we have the reviews regularly and they have perhaps a better relationship with other therapists, they can have the ability to actually show bits of creativity themselves and have discussions and make suggestions... Perhaps it does encourage provider teams to be more aware of what's going on and therefore more focussed on the person.
There was some indication that there were better relationships with some providers than others and that some engaged more with the pathways. Staff groups who understood the dementia processes and attended training were seen as more amenable to professionals conducting assessments, giving advice and making referrals.

\section{7 | The wider service context}

Participants identified a number of external influences impacting on support received by people with learning disabilities and dementia, including the availability, appropriateness, cost and effectiveness of different models of service provision. Examples were given of people who had been supported to stay at home, the preferred option; however, these were exceptions. Barriers to remaining at home included the following: concerns about safety, the physical environment, planning for environmental adaptations based on predicted need, availability of appropriate 24 -hour support, financial structures and budgets:

Care Manager: One of the problems would be that people who have lived independently not with family, and not with 24-hr support and they develop dementia...for the person I'm thinking about from last year we couldn't effectively have provided 24-hr support in her own home because the type of carers who do that aren't facilitated to work around the clock and don't do overnight work so it was totally impractical really.

There was a shortage of specific dementia services tailored for people with learning disabilities. The majority of available placements were designed for older people and viewed as inappropriate for younger people with learning disabilities and dementia who are likely to be more active and mobile. Concerns were expressed that staff in settings for older people are not trained to support people with learning disabilities, provide appropriate interaction or recognise potential health problems. Furthermore, the use of large nursing homes or residential placements conflicts with the philosophy of smaller placements within learning disability service provision:

\footnotetext{
Care manager: In learning disability we don't seem to generally place people or have placements that are for 20 odd, 30 odd people. And yet when you come to look at residential and nursing placements where dementia care can be provided, they're big. And it's something we've got away from in the last, well we were getting away from that when I started 30 odd years ago. So it's a bit of a shock really that we're back to something that's vast really, where our people just get lost.
}

There was some uncertainty about which was the most appropriate, cost-effective approach. It was felt that there were a number of potential options, each with advantages and disadvantages: 
Psychologist C: You could try to embed people with dementia and a learning disability into the more generic learning disability type placements and skill those people up or do you focus all the expertise into learning disability specific dementia type placements? I've no idea what the right answer is... Would it be to put in place training and additional support into places people already live or concentrating it into larger specialist units?

Whilst the pathways had increased clarity of roles within community learning disability teams, issues remained about the roles and involvement of other healthcare providers; for example, the role of psychiatry and GPs post-diagnosis and geographical variation in memory clinic involvement:

Nurse: ...the memory service is changing and in the past it changed depending which part of the city the person lives. Like the south could access the memory clinic but obviously depending on the part of the city, the psychiatry service is changing. Some psychiatrists would let the GP do it and some wouldn't

Concerns were raised about the impact of going into hospital for people with learning disabilities and dementia which could lead to deterioration if people became confused in an unfamiliar place, caught infections or were fed inappropriately. There were also concerns about the use of Do Not Resuscitate (DNR) orders:

Psychologist A: ...people go into hospital and a DNR is put on them because they've got a diagnosis of dementia even though there's no clear process of how the decision-making has been ...that's really distressing for family and carers particularly if people are early on in the process and aren't that unwell but people are talking because they've got a learning disability, they can't communicate...I think decisions being made about their quality of life without maybe appropriate consultation.

TAB LE 2 Service developments resulting from the evaluation findings

\begin{tabular}{|c|c|}
\hline Issue identified & Service developments \\
\hline \multirow{6}{*}{$\begin{array}{l}\text { Support and } \\
\text { education for } \\
\text { carers }\end{array}$} & StaRT (Strategies for RelaTives) support and education programme is being piloted with family carers and a staff team. \\
\hline & $\begin{array}{l}\text { Connections made with dementia advisors in the mental health trust, who are invited to initial dementia interventions reviews to } \\
\text { ensure carers are aware of local services and support available to the general population with dementia. }\end{array}$ \\
\hline & Training now offered as a 2-day package once a year; this has been trialled and found to work well. \\
\hline & Exploring possibility of "Top Tips" sheets being translated into other languages to meet local population needs \\
\hline & Carers asked how they would like to receive information. \\
\hline & $\begin{array}{l}\text { Nursing homes supporting people with learning disabilities receive information about dementia training and are involved in } \\
\text { dementia review meetings where training needs are discussed. }\end{array}$ \\
\hline $\begin{array}{l}\text { Interventions } \\
\text { checklist }\end{array}$ & $\begin{array}{l}\text { No longer needs to be routinely completed during a review meeting but should be referred to by the clinician chairing the review } \\
\text { to ensure that all potentially beneficial interventions have been offered. }\end{array}$ \\
\hline \multirow{2}{*}{$\begin{array}{l}\text { Involving } \\
\text { people with } \\
\text { learning } \\
\text { disabilities }\end{array}$} & $\begin{array}{l}\text { The option now exists to hold reviews in people's homes to support them to be more relaxed and to facilitate them to come in } \\
\text { and out if this is more manageable for them. }\end{array}$ \\
\hline & Strategies to involve people have been discussed. \\
\hline \multirow[t]{2}{*}{ End of Life } & $\begin{array}{l}\text { Need to clarify who finds discussions around end of life difficult (i.e., people with learning disabilities, families, support workers, } \\
\text { community learning disability team members) and how to facilitate these discussions. }\end{array}$ \\
\hline & Dementia and end of life working groups are working closely together on this issue. \\
\hline \multirow{6}{*}{$\begin{array}{l}\text { Developing } \\
\text { links with } \\
\text { service } \\
\text { providers and } \\
\text { commissioners }\end{array}$} & Commissioners now link into the Dementia Working Group and have begun to discuss this service need with providers. \\
\hline & Closer links are being developed with the local providers' forum. \\
\hline & $\begin{array}{l}\text { Dementia pathways have been revised in collaboration with local memory services which has helped to establish good working } \\
\text { relationships and clarify roles and the referral process. }\end{array}$ \\
\hline & $\begin{array}{l}\text { To improve experiences in hospital, the dementia lead now attends the hospital trust's dementia strategy meetings and links are } \\
\text { being developed with dementia leads, champions and learning disability liaison nurses based in hospitals across the city. } \\
\text { Discussions are also taking place around offering training to trainee doctors. }\end{array}$ \\
\hline & $\begin{array}{l}\text { A number of steps have been taken to improve GP awareness of learning disabilities and dementia and to avoid misunderstand- } \\
\text { ings around diagnosis. }\end{array}$ \\
\hline & $\begin{array}{l}\text { Nursing team has developed an information booklet around health conditions that are more common for people with Down's } \\
\text { syndrome and screening needed around these which is being sent to carers and GPs. }\end{array}$ \\
\hline \multirow{2}{*}{$\begin{array}{l}\text { Evidence-based } \\
\text { practice }\end{array}$} & Up-to-date evidence is circulated as it is published \\
\hline & $\begin{array}{l}\text { Undertaking a literature review around interventions for people with a learning disability and dementia and carers published in } \\
\text { the last } 5 \text { years to inform clinical practice and training }\end{array}$ \\
\hline
\end{tabular}




\section{4 | DISCUSSION}

The aim of the evaluation was to review the effectiveness of pathways and supports developed to improve local services for people with learning disabilities and dementia. The evaluation indicates that local dementia processes for people with learning disabilities and carers generally work well. The findings have led to a number of service developments (Table 2 ) and contribute to the existing evidence base.

The findings show that dementia screening and pathways have become embedded within practice, providing health and social care professionals with a common framework and facilitating a co-ordinated, efficient, multidisciplinary approach. This reflects findings from other adult learning disability services in the United Kingdom that introducing care pathways improves communication and information-gathering, strengthens multidisciplinary working, leads to more co-ordinated, standardised care and reduces duplication, benefiting clients (Ahmad et al., 2007; Wood et al., 2014). In the wider research literature, concerns about care pathways surround: restricting the ability to apply clinical judgement; stifling innovation and progress; and the need for leadership, good communication and time to implement pathways. Barriers to implementation include reluctance to change, lack of a suitable evidence base and interpersonal politics (Campbell, Hotchkiss, Bradshaw, \& Porteous,1998). That such concerns and barriers were not raised here could be because the pathways' implementation was well led and the service has a long history of multidisciplinary working; key factors in the success of care pathways (Kent \& Chalmers, 2006).

The British Psychological Society (2015) describes ageing and "dying in place" at home as the preferred option for people with learning disabilities and dementia, specialist learning disability provision as a compromise option and referral out of learning disability services (e.g., to residential or nursing home) as the least preferred option. This evaluation raises issues about the availability of appropriate accommodation and support for people with learning disabilities and dementia and concerns about the use of nonspecialist provision, both nonlearning disability and nondementia specialist provision. Coherent strategies and adequate resources are important to ensure that people are not moved inappropriately to nursing homes for older people (Wilkinson, Kerr, Colm Cunningham, \& Rae, 2004), and although not widely available, there is some evidence that specialist services developed for people with learning disabilities with dementia appear to work well (Kalsy et al., 2005).

Forbat and Wilkinson (2008) argue that policy and practice tend to be based on assumptions rather than evidence about the types of model of care and service provision that are most appropriate for people with learning disabilities and dementia. Their analysis of qualitative data from people with learning disabilities who had dementia or were living with someone with dementia found significant fears and expectations about generic care homes and challenged the assumption that ageing in place is always the preferred option if this has a negative impact on other residents and if the person with dementia lacks knowledge and awareness about dementia and its impact on self and other people. Further evidence and debate around the impact of different models of support and their acceptability to people with learning disabilities and families is clearly required.

It is of interest that participants did not discuss which interventions are effective and appropriate for people with learning disabilities and dementia, instead focusing on more general models of service provision. This could be because participants felt well informed about existing interventions, possibly due to the use of the Dementia Interventions checklist. However, the limited evidence about the effectiveness of interventions for people with dementia with and without learning disabilities demonstrates a need for further research and sharing of research findings within learning disability services to help inform decisions about which interventions to use.

The importance of support and information for caregivers is clear from this study. Caring for people with learning disabilities and dementia is time-consuming and often stressful (Cleary \& Doody, 2017). Common behaviours such as lack of energy, sleep disturbance, incontinence, mealtime problems, agitation and aggression can be difficult to manage, leading to emotional and physical strain, impacting on the viability of a residential placement (Furniss, Loverseed, Lippold, \& Dodd, 2012; Lloyd, Kalsy, \& Gatherer, 2008). Caregivers may have limited understanding of dementia's impact and useful strategies to respond to changes and may reject input (Cleary \& Doody, 2017; lacono et al., 2014). Caregivers need to be informed; for example, through involvement in assessments and reviews, reports, information about dementia, services and strategies to support people with learning disabilities and dementia (Furniss et al., 2012).

This evaluation suggests that training for carers, regular reviews and the "Top Tips" information sheets work well in terms of awarenessraising, helping carers support people proactively, improving carers' knowledge of and engagement with local services and reducing crisisbased input. A personalised approach is important; for example, format and amount of information. There is some evidence about the impact of training for paid carers. For example, Houghton, McNally, and Scanlon (2013) report on a 1-day training programme for day care staff working in Social Education Centres developed and delivered by Clinical Psychology and Occupational Therapy teams. Approximately half of participants had no prior training in dementia and felt that the training had improved their confidence in supporting people with learning disabilities and dementia. Participants particularly valued being able to take time out and view things from the perspective of the person with learning disabilities. A study in Ireland found that educational programmes for staff in learning disabilities and palliative care providers can support "ageing in place" and the preparation for a "good death" (Fahey-McCarthy, McCarron, Connaire, \& McCallion, 2009).

In addition to improving carer knowledge and skills, it is important to identify ways to address staff and family stress. In the general population, the StaRT (Strategies for RelaTives) support and education programme has been found to be clinically and cost-effective for family carers (Knapp et al., 2013; Livingston et al., 2013) and positively received by carers (Middleton \& Mason, 2017; Sommerlad, Manela, Cooper, Rapaport, \& Livingston, 2014). This programme is being piloted locally with family carers and a staff team to see how appropriate it is for carers of people with learning disabilities. 
Whilst participants discussed support and training provided for families and paid carers, there was no discussion of the potential need for support and training for a person's housemates and peers with learning disabilities. Lynggaard and Alexander (2004) found that housemates living with someone with learning disabilities could experience confusion and frustration at changes in fellow resident who they may have known for many years. They describe a group intervention with four residents living with two other people with Down's Syndrome and a diagnosis of dementia to help explain dementia and provide a space to discuss the impact of living with someone who develops dementia. The group helped participants to recognise that changes in their housemates were the result of an illness over which the people with dementia might not have control and provided knowledge of practical ways in which they could support their housemates with dementia. Dodd (2008) also describes successful short courses for people with learning disabilities living with someone with dementia

Issues around end of life were raised by participants, and this was clearly difficult for families and staff to deal with. It was also difficult to follow the service's end of life processes in a timely manner. These issues have been raised in other studies with learning disability service providers and palliative care services, and a stronger evidence base is needed on the timing and efficacy of palliative care for people with learning disabilities and dementia (McCarron, McCallion, FaheyMcCarthy, \& Connaire, 2010, 2011). Locally, work to develop services and support in this area is ongoing.

Another issue identified from the focus group discussion was that people with learning disabilities and dementia are not always involved in reviews and professionals are not always clear about how best to do this. It is important to consider how to ensure that people with learning disabilities are meaningfully involved. This is likely to involve a range of approaches depending on individual skills and preferences.

The community learning disability services are based within a multicultural area; however, there was no mention of the potential impact of cultural background on the services and supports needed by people with learning disabilities and dementia and their families. This may reflect that participants felt that the needs of people from a range of cultural backgrounds are being well met; alternatively, it may indicate that further cultural awareness is needed amongst local learning disability services. The British Psychological Society (2015) draws attention to the need for further research to understand the views of people with learning disabilities and dementia from Black and Minority Ethnic communities and their carers and identify culturally appropriate ways of meeting their needs.

\subsection{Limitations of the evaluation}

This evaluation has enabled our service to reflect on and refine current processes and identify additional areas to consider. There was a small sample size as it was only possible to carry out one focus group due to service delivery demands. There were a number of potential sources of bias within the sample. There was no representation from physiotherapy so their viewpoint was not included and there were more participants from Psychology and Behavioural Support, probably as this professional group leads on the dementia work. The sample was selfselecting and as a result tended to consist of people with an interest in dementia; participants' views may not reflect views of health and social care staff who were not involved in the focus group, or who have not been so closely involved in the dementia processes. Participants were known to each other which may impact on the findings as they may have felt that they needed to respond in ways which were acceptable to the service or their colleagues, despite assurances of anonymity. An in-house researcher and the assistant psychologist who conducts the majority of screening assessments facilitated the focus group. This potential for bias was partly addressed by involving a clinician who was not present at the focus group in analysis. Finally, the findings reflect the priorities, views and experiences of professionals, rather than those of people with learning disabilities, families and support staff.

\section{5 | CONCLUSIONS}

This evaluation suggests that dementia pathways and supports can improve service provision and outcomes for people with learning disabilities and dementia. Although a small-scale evaluation, we hope that the findings and consequent service developments will be useful to other service providers and commissioners. It is vital to develop the evidence base on people with learning disabilities and dementia, in particular, the effectiveness of different approaches and models of service provision. Research in dementia is high priority internationally, and it is important to ensure that people with learning disabilities participate in research. Specialist learning disability services can play an important role informing people of the importance of research and studies that they can get involved with (British Psychological Society, 2015). However, existing research may exclude people with learning disabilities, may not have accessible information or methods and may not make reasonable adjustments to interventions being evaluated. It is important that future studies ensure that they are accessible to people with learning disabilities and include the perspectives of people with learning disabilities, their organisations, families and paid carers.

\section{ORCID}

Melanie Chapman (iD http://orcid.org/0000-0001-6668-1273

Nicola Jervis (iD http://orcid.org/0000-0002-8638-3254

\section{REFERENCES}

Ahmad, F., Roy, A., Brady, S., Belgeonne, S., Dunn, L., \& Pitts, J. (2007). Care pathway initiative for people with intellectual disabilities: Impact evaluation. Journal of Nursing Management, 15, 700-702. https://doi. org/10.1111/j.1365-2934.2006.00734.x

Alzheimer's Society (2014). Dementia UK: Update. London: Alzheimer's Society.

Backer, C., Jervis, N. (2007). Health conditions and health screening in Adults with Down's syndrome. Nursing Times, 103, 30-31. 
Braun, V., \& Clarke, V. (2006). Using thematic analysis in psychology. Qualitative Research in Psychology, 3, 77-101. https://doi.org/10.1191 /1478088706qp063oa

British Psychological Society (2015). Dementia and People with Intellectual Disabilities Guidance on the assessment, diagnosis, interventions and support of people with intellectual disabilities who develop dementia. Leicester, UK: The British Psychological Society.

Cairns, V., Lamb, I., \& Smith, E. (2010). Reflections upon the development of a dementia screening service for individuals with Down's syndrome across the Hyndburn and Ribble ValleyArea. British Journal of Learning Disabilities, 39, 198-208.

Campbell, H., Hotchkiss, R., Bradshaw, N., \& Porteous, M. (1998). Integrated care pathways. British Medical Journal, 316, 133-137. https://doi. org/10.1136/bmj.316.7125.133

Cleary, J., \& Doody, O. (2017). Professional carers' experiences of caring for individuals with intellectual disability and dementia: A review of the literature. Journal of Intellectual Disabilities, 21, 68-86. https://doi. org/10.1177/1744629516638245

Courtenay, K., Jokinen, N., \& Strydom, A. (2010). Caregiving and adults with intellectual disabilities affected by dementia. Journal of Policy and Practice in Intellectual Disabilities, 7, 26-33. https://doi. org/10.1111/j.1741-1130.2010.00244.x

Crook, N., Adams, M., Shorten, N., \& Langdon, P. (2016). Does the wellbeing of individuals with down syndrome and dementia improve when using life story books and rummage boxes? A randomized single case series experiment. Journal of Applied Research in Intellectual Disabilities, 29, 1-10. https://doi.org/10.1111/jar.12151

De Vreese, L., Mantesso, U., De Bastiani, E., Weger, E., Marangoni, A., \& Gomiero, T. (2012). Impact of dementia-derived nonpharmacological intervention procedures on cognition and behavior in older adults with intellectual disabilities: A 3-year follow-up study. Journal of Policy and Practice in Intellectual Disabilities, 9, 92-102. https://doi. org/10.1111/j.1741-1130.2012.00344.x

Department of Health (2001). Valuing People: A new strategy for learning disability for the 21st century. London, UK: Department of Health.

Department of Health (2009). Living well with dementia: A National Dementia Strategy. Leeds, UK: Department of Health.

Department of Health (2012). Prime Minister's Challenge on Dementia Delivering major improvements in dementia care and research by 2015. Leeds, UK: Department of Health.

Department of Health (2015). Prime Minister's challenge on dementia 2020. London: Williams Lea.

Department of Health, Social Services and Public Safety, Northern Ireland (2011). Improving dementia services in Northern Ireland - A regional strategy. Retrieved from https://www.health-ni.gov.uk/sites/default/files/ publications/dhssps/improving-dementia-services-2011.pdf.

Dodd, K. (2008). Transition to old age - what can we do to aid the process? Advances in Mental Health and Learning Disabilities, 2, 7-12. https://doi. org/10.1108/17530180200800023

Fahey-McCarthy, E., McCarron, M., Connaire, K., \& McCallion, P. (2009). Developing an education intervention for staff supporting persons with an intellectual disability and advanced dementia. Journal of Policy and Practice in Intellectual Disabilities, 6, 267-275. https://doi. org/10.1111/j.1741-1130.2009.00231.x

Forbat, L., \& Wilkinson, H. (2008). Where should people with dementia live? Using the views of service users to inform models of care. British Journal of Learning Disabilities, 36, 6-12. https://doi. org/10.1111/j.1468-3156.2007.00473.x

Furniss, K. A., Loverseed, A., Lippold, T., \& Dodd, K. (2012). The views of people who care for adults with Down's syndrome and dementia: a service evaluation. British Journal of Learning Disabilities, 40, 318-327. https://doi. org/10.1111/j.1468-3156.2011.00714.x

Hanney, M., Prasher, V., Williams, N., Llones, E., Aarsland, D., Corbett, A., ... Ballard, C. (2012). Memantine for dementia in adults older than
40 years with Down's syndrome (MEADOWS): A randomised, doubleblind, placebo-controlled trial. Lancet, 379, 528-536. https://doi. org/10.1016/S0140-6736(11)61676-0

Hobson, B., Webb, D., Sprague, L., Grizzell, M., Hawkins, C., \& Benbow, S. M. (2012). Establishing a database for proactive screening of adults with Down's syndrome: when services work together. Advances in Mental Health and Intellectual Disabilities, 6, 99-105. https://doi. org/10.1108/20441281211208464

Houghton, P., McNally, P., \& Scanlon, M. (2013). Learning disability and dementia: Audit of staff training pilot. Clinical Psychology \& People with Learning Disabilities, 11, 28-31.

lacono, T., Bigby, C., Carling-Jenkins, R., \& Torr, J. (2014). Taking each day as it comes: Staff experiences of supporting people with Down syndrome and Alzheimer's disease in group homes. Journal of Intellectual Disability Research, 58, 521-533. https://doi.org/10.1111/jir.12048

Janicki, M. P., Zendell, A., \& DeHaven, K. (2010). Coping with dementia and older families of adults with Down syndrome. Dementia, 9, 391-407. http://doi.org/10.1177/1471301210375338

Jervis, N., \& Prinsloo, L. (2008). How we developed a multidisciplinary screening project for people with Down's syndrome given the increased prevalence of early onset dementia. British Journal of Learning Disabilities, 36, 13-21. https://doi. org/10.1111/j.1468-3156.2007.00474.x

Kalsy, S., McQuillan, S., Adams, D., Tarvinder, B., Konstantinidi, E., Broquard, M., ... Oliver, C. (2005). A proactive psychological strategy for determining the presence of dementia in adults with Down Syndrome: Preliminary description of service use and evaluation. Journal of Policy and Practice in Intellectual Disabilities, 2, 116-125. https://doi. org/10.1111/j.1741-1130.2005.00025.x

Kent, P., \& Chalmers, Y. (2006). A decade on: Has the use of integrated care pathways made a difference in Lanarkshire? Journal of Nursing Management, 14, 508-520. https://doi. org/10.1111/j.1365-2934.2006.00707.x

Kitzinger, J. (2006). Focus groups. In C. Pope, \& N. Mayes (Eds.), Qualitative research in health care. Oxford, UK: Blackwell Publishing Ltd.

Knapp, M., King, D., Romeo, R., Schehl, B., Barber, J., Griffin, M., ... Livingston, G. (2013). Cost effectiveness of a manual based coping strategy programme in promoting the mental health of family carers of people with dementia (the START (STrAtegies for RelaTives) study): A pragmatic randomised controlled trial. British Medical Journal, 347, F6342. https://doi.org/10.1136/bmj.f6342

Krueger, R. A., \& Casey, M. A. (2000). Focus groups: A practical guide for applied research. London, UK: Sage. https://doi.org/10.1037/10518-000

Livingston, G., Barber, J., Rapaport, P., Knapp, M., Griffin, M., King, D., ... Cooper, C. (2013). Clinical effectiveness of a manual based coping strategy programme (START, STrAtegies for RelaTives) in promoting the mental health of carers of family members with dementia: Pragmatic randomised controlled trial. British Medical Journal, 347, F6276. https:// doi.org/10.1136/bmj.f6276

Lloyd, V., Kalsy, S., \& Gatherer, A. (2008). Impact of dementia upon residential care for individuals with down syndrome. Journal of Policy and Practice in Intellectual Disabilities, 5, 33-38. https://doi. org/10.1111/j.1741-1130.2007.00137.x

Lynggaard, H., \& Alexander, N. (2004). 'Why are my friends changing?' Explaining dementia to people with learning disabilities. British Journal of Learning Disabilities, 32, 30-34. https://doi. org/10.1111/j.1468-3156.2004.00246.x

McCarron, M., McCallion, P., Fahey-McCarthy, E., \& Connaire, K. (2010). Staff perceptions of essential prerequisites underpinning end-of-life care for persons with intellectual disability and advanced dementia. Journal of Policy and Practice in Intellectual Disabilities, 7, 143-152. https://doi.org/10.1111/j.1741-1130.2010.00257.x

McCarron, M., McCallion, P., Fahey-McCarthy, E., \& Connaire, K. (2011). The role and timing of palliative care in supporting persons with intellectual disability and advanced dementia. Journal of 
Applied Research in Intellectual Disabilities, 24, 189-198. https://doi. org/10.1111/j.1468-3148.2010.00592.x

Middleton, E., Mason, D. (2017). Coping with caring. OT News, July, 24-25.

Mohan, M., Bennett, C., Carpenter, P. (2009a). Rivastigmine for dementia in people with Down syndrome. Cochrane Database of Systematic Reviews, 1, CD0076598.

Mohan, M., Bennett, C., Carpenter, P. (2009b). Galantamine for dementia in people with Down syndrome. Cochrane Database of Systematic Reviews, 1, CD007656.

Mohan, M., Carpenter, P., Bennett, C. (2009). Donepezil for dementia in people with Down syndrome. Cochrane Database of Systematic Reviews, 1, CD007178.

NICE (2006). Dementia: supporting people with dementia and their carers in health and social care: NICE guidelines [CG42].

Scottish Government (2013). Scotland's National Dementia Strategy 2013-2016. Retrieved from http://www.scotland.gov.uk/ Resource/0042/00423472.pdf.

Sheehan, R., Afia, A., \& Hassiotis, A. (2014). Dementia in intellectual disability. Current Opinion in Psychiatry, 27, 143-148. https://doi. org/10.1097/YCO.0000000000000032

Sommerlad, A., Manela, M., Cooper, C., Rapaport, P., \& Livingston, G. (2014). START (STrAtegies for RelaTives) coping strategy for family carers of adults with dementia: Qualitative study of participants' views about the intervention. British Medical Journal Open, 4, e005273.

Spector, A., Thorgrimsen, L., Woods, B., Royan, L., Davies, S., Butterworth, M., \& Orrell, M. (2003). Efficacy of an evidence-based cognitive stimulation therapy programme for people with dementia: Randomised controlled trial. British Journal of Psychiatry, 183, 248-254. https://doi. org/10.1192/bjp.183.3.248

Starkey, H., Bevins, S., \& Bonell, S. (2014). The role of prospective screening in the diagnosis of dementia in people with Down's syndrome. Advances in Mental Health and Intellectual Disabilities, 8, 283-291. https://doi.org/10.1108/AMHID-12-2013-0067
Stueber, K., \& Hassiotis, A. (2012). Reminiscence therapy for older service users. Learning Disability Practice, 15, 12-16. https://doi.org/10.7748/ Idp2012.03.15.2.12.c8965

Turk, V., Dodd, K., \& Christmas, M. (2001). Down's syndrome and dementia: Briefing for commissioners. London, UK: Foundation for People with Learning Disabilities.

Ward, A., \& Parkes, J. (2017). An evaluation of a Singing for the Brain pilot with people with a learning disability and memory problems or a dementia. Dementia, 16, 360-374. https://doi.org/10.1177/1471301215592539

Welsh Assembly Government (2011). National dementia vision for Wales. Retrieved from http://wales.gov.uk/docs/dhss/publications/110302dementiaen.pdf.

Wilkinson, H., Kerr, D., Colm Cunningham, C., \& Rae, C. (2004). Home for Good? Preparing to support people with learning difficulties in residential settings when they develop dementia. New York, NY, USA: Joseph Rowntree Foundation.

Wood, S., Gangadharan, S., Tyrer, F., Gumber, R., Devapriam, J., Hiremath, A., \& Bhaumik, S. (2014). Successes and challenges in the implementation of care pathways in an intellectual disability service: Health professionals' experiences. Journal of Policy and Practice in Intellectual Disabilities, 11, 1-7. https://doi.org/10.1111/jppi.12063

\section{How to cite this article: Chapman M, Lacey H, Jervis N.}

Improving services for people with learning disabilities and dementia: Findings from a service evaluation exploring the perspectives of health and social care professionals. $\mathrm{Br} J$ Learn Disabil. 2018;46:33-44. https://doi.org/10.1111/bld.12210 